\title{
Concepções de tutores de sede de um curso de pedagogia na modalidade a distância acerca do conceito de interdisciplinaridade
}

\author{
Simone Bicca Charczuk ${ }^{1}$ \\ Tania Beatriz Iwaszko Marques ${ }^{2}$
}

\section{Resumo}

Visando a contribuir com as discussões acerca dos temas tutoria em EaD e interdisciplinaridade, a partir da perspectiva piagetiana, investigamos quais são as concepções de interdisciplinaridade expressas por tutores de sede de um curso de pedagogia na modalidade a distância que atuaram em interdisciplinas que diferiram da sua área de formação inicial. Para tanto, realizamos um estudo de caso exploratório com 11 tutores de sede que responderam um questionário enviado por e-mail. As respostas foram analisadas a partir da análise de conteúdo. As concepções de interdisciplinaridade, expressas pelos tutores, aproximaram-se do conceito piagetiano de multidisciplinaridade, embora alguns tutores tenham expressado concepções afins ao conceito de interdisciplinaridade. Este trabalho demonstra uma aproximação inicial com os temas e ressalta a relevância dos mesmos para o contexto educativo.

Palavras-chave: Tutoria; Interdisciplinaridade; Educação a distância.

Conceptions de tuteurs du siège d'un cours de pédagogie à distance sur le concept de l'interdisciplinarité

\section{Résumé}

Visant à contribuer a des discussions sur les sujets tutorat dans l'éducation à distance et l'interdisciplinarité dans la perspective piagétienne, nous examinons quelles sont les concepts d'interdisciplinarité exprimées par les tuteurs du siège d'un cours de pédagogie à distance qui ont agi en interdisciplines qui diffèrent de son domaine de formation initiale. Ainsi, nous avons effectué une étude de cas exploratoire avec 11 tuteurs qui ont répondu à un questionnaire envoyé par e-mail. Les réponses ont été analysées à partir de l'analyse de contenu. Les conceptions de l'interdisciplinarité exprimées par les tuteurs abordent la notion piagétienne de la multidisciplinarité, même si certains sujets ont exprimé des point de vues analogues à la notion d'interdisciplinarité. Ce travail démontre une première approche des ces thèmes et souligne son pertinence pour le contexte éducatif.

Mots-clés: Tutorat; Interdisciplinarité; Education à distance.

\footnotetext{
${ }^{1}$ Professora do Curso de Psicologia da UNISINOS. Tutora do Curso de Pedagogia a Distância da UFRGS. Psicóloga e Mestre em Saúde Coletiva. E-mail: sibicca@gmail.com.

2 Professora de Psicologia da Educação na Faculdade de Educação da Universidade Federal do Rio Grande do Sul. Doutora em Educação. Integrante do NEEGE. E-mail: taniabimarques@bol.com.br.
} 


\section{Introdução}

A Educação a Distância (EaD), como modalidade educativa que vem ganhando espaço no cenário educacional brasileiro, conta, atualmente, com mais um sujeito que participa deste contexto, além da dupla professor-aluno: o tutor. A figura do tutor surgiu nas Universidades do século $\mathrm{XV}$, carregada de caráter religioso na orientação aos estudantes. Sua tarefa estava ligada a guiar os alunos nos seus estudos. Já no século XX o tutor assume o papel de acompanhar o trabalho acadêmico dos estudantes e é esse sentido que é incorporado à tutoria nos cursos de EaD (MACHADO e MACHADO, 2004). De acordo com os Referenciais de Qualidade para a Educação Superior a Distância, o tutor deve ter um papel ativo na prática pedagógica dos cursos, além do que "suas atividades devem contribuir para o desenvolvimento dos processos de ensino e de aprendizagem e para o acompanhamento e avaliação do projeto pedagógico do curso" (BRASIL, 2007, p. 21). A fim de que o tutor possa contribuir com os processos de ensino e de aprendizagem nessa modalidade, é de suma importância que as especificidades do seu trabalho possam ser definidas. Nepomuceno, Salles e Pan (2004, p. 2) destacam o papel do tutor como essencial, afirmando que “devemos vê-lo como uma 'ponte móvel' entre o aluno, o curso e o professor". No que se refere aos conhecimentos necessários para a realização do trabalho de tutoria, Machado e Machado (2004) referem que o tutor necessita compreender o assunto com o qual está trabalhando e tal compreensão pode ser construída a partir de uma formação teórica realizada na própria formação prática dos espaços tutoriais.

Também existem características diferenciadas entre os papéis do tutor que atua nos polos e de tutores que atuam nas sedes dos cursos. No documento Referencias de Qualidade (BRASIL, 2007), já citado anteriormente, é apresentada a distinção entre o tutor presencial e o tutor a distância. $\mathrm{O}$ tutor presencial é responsável pelo atendimento aos alunos diretamente nos polos, 


\section{Şchème \\ Revista Eletrônica de Psicologia e Epistemologia Genéticas}

auxiliando-os na realização das atividades, nos conteúdos das disciplinas e no manejo das tecnologias. Já o tutor a distância atende os alunos a partir da instituição, principalmente, esclarecendo dúvidas diretamente vinculadas ao conteúdo das disciplinas por meio de diversos recursos comunicacionais, tais como o ambiente virtual utilizado, e-mail, MSN etc. Embora essas definições sobre tutoria e tutor auxiliem na compreensão das características deste participante do cenário educacional na modalidade EaD, podemos dizer que a função do tutor ainda está em construção (ZIEDE, 2008). Além disso, tal função e seus encargos irão depender da organização didático-pedagógica de determinado curso.

No Curso $^{3}$ eleito para a realização deste trabalho, os tutores também exercem as funções de tutores presencias e tutores a distância. Os tutores presenciais, ou tutores de polo, não possuem necessariamente formação específica nas interdisciplinas do curso. A função geral desses tutores é incentivar os alunos, promover o diálogo, a orientação individual e coletiva nas atividades que ocorrem presencialmente, principalmente, promovendo o vínculo com cada aluno (NEVADO, CARVALHO e BORDAS, 2006, p. 26). Os tutores a distância, ou tutores de sede, possuem formação nas interdisciplinas, provinda de seus cursos de graduação de origem ou construída no curso de especialização em tutoria ${ }^{4}$. Esses tutores devem acompanhar e facilitar o acesso dos alunos aos

3 O Curso, oferecido na modalidade de projeto, iniciou em 2006/2. Seu público-alvo são 400 professores (professoras, na sua maioria) que trabalham nas redes municipais e/ou estaduais do Rio Grande do Sul e que não possuem formação superior em pedagogia. Os polos do curso localizam-se nas cidades de Alvorada, Gravataí, Sapiranga, São Leopoldo e Três Cachoeiras. O currículo é organizado em interdisciplinas (compreendidas como áreas para as quais convergem diferentes disciplinas, mesmo que uma delas seja predominante em determinado momento) que visam a relacionar o conhecimento teórico e prático ao longo dos semestres. Em cada interdisciplina trabalham um professor e um ou dois tutores, dependendo da carga horária da interdisciplina. Trabalha ainda com a proposta de Seminários Integradores, que ocorrem em todos os semestres do curso, visando a garantir as interrelações tanto dos componentes interdisciplinares do currículo, quanto da equipe que trabalha em cada polo durante o semestre.

4 O Curso de Especialização em Tutoria (ESPEAD) foi criado em 2007 e todos os tutores que trabalham no curso foram a ele vinculados. A especialização é realizada de forma presencial e a distância. Geralmente, os encontros presenciais são reservados para reunião das equipes de tutores e professores e para as formações nas interdisciplinas em cada início do semestre. Nestas formações, os tutores entram 
conteúdos e atividades propostas pelas interdisciplinas, comentar trabalhos e esclarecer dúvidas, a partir da orientação dos professores (NEVADO, CARVALHO e BORDAS, 2006, p. 27).

Uma das especificidades do trabalho dos tutores de sede neste curso é que eles mantêm-se vinculados ao trabalho de tutoria ao longo dos nove semestres, ou seja, em cada semestre acompanham uma interdisciplina, sendo que acompanham não somente disciplinas afins a sua área de formação inicial. Nesse sentido, os tutores que possuem formações específicas em outras áreas que não a pedagogia deparam-se, em algum momento do seu trabalho como tutor, com a necessidade de acompanhar as atividades dos alunos cujo conteúdo difere, de algum modo, daqueles trabalhados na sua formação na graduação. Assim, podemos compreender que tal necessidade implica uma aproximação com o conceito de interdisciplinaridade. Vários autores dedicam seus trabalhos a este conceito, porém, nesta pesquisa vamos enfatizar a interdisciplinaridade segundo Piaget, pois, de acordo com Thiesen (2008), as obras piagetianas serviram de base para fomentar discussões de pesquisadores brasileiros acerca do conceito. Soma-se a isso o fato da teoria piagetiana embasar a proposta pedagógica do curso, principalmente no que diz respeito à concepção de aprendizagem e de intervenção pedagógica.

No que se refere ao conceito de interdisciplinaridade, o pesquisador genebrino dedicou alguns artigos e livros ao seu estudo (CHARCZUK e NEVADO, 2009). Nestas obras, concebe-a como colaboração entre diversas disciplinas que conduz a interações nas quais se estabelecem reciprocidades nas trocas e que possibilitam um enriquecimento mútuo das disciplinas envolvidas, ou seja, onde exista assimilação recíproca (PIAGET, 1966, 1971a, 1971b, 1972, 1973a). Rolando Garcia, colaborador de Piaget, também se dedicou ao estudo do

em contato com os materiais das interdisciplinas, debatem com os professores a sua organização e esclarecem dúvidas em relação aos conteúdos das mesmas, cooperando, desta forma, com a elaboração da proposta pedagógica da interdisciplina. 
conceito. Segundo Garcia (2007), para haver interdisciplinaridade é necessária a integração de diferentes enfoques disciplinares. Nesse sentido, cada membro de uma equipe deve ser expert na sua disciplina e, ao mesmo tempo, realizar um distanciamento das especificidades desta a partir da abertura a métodos, conceitos e linguagens pouco familiares, provindos das demais disciplinas com as quais busca o diálogo. Destaca ainda que, para uma prática interdisciplinar se efetivar, é importante o trabalho conjunto de profissionais de várias áreas, porém, este estar junto não é suficiente. A justaposição de especialistas não produz a interdisciplinaridade. Para que isso seja possível, é necessário que haja trabalho cooperativo. Piaget $(1973 b, 1998)$ concebe o conceito de cooperação como uma ação que é realizada em comum, na qual os sujeitos ajustam, por meio de novas operações, correspondência, reciprocidade ou complementaridade, as operações que são realizadas por cada participante. A partir da relação cooperativa, o sujeito pode modificar seu ponto de vista ou coordená-lo com os pontos de vista de diversos sujeitos.

Tendo em vista a necessidade dos tutores de sede envolver-se em práticas interdisciplinares no acompanhamento do trabalho dos alunos no curso e a especificidade do conceito de interdisciplinaridade, conforme proposto por Piaget e Garcia, neste trabalho, investigamos as concepções de interdisciplinaridade expressas por tutores de sede que atuaram no curso em interdisciplinas, cujo conteúdo curricular diferiu daqueles comumente abordados na sua área de formação na graduação. 


\section{Caminhos Metodológicos}

Este estudo, caracterizado como estudo de caso de caráter exploratório (YIN, 2005), contou com a participação de 11 tutores de sede, o que corresponde a $24,4 \%$ do total de tutores que trabalham atualmente neste contexto ${ }^{5}$. Dos participantes, nove são mulheres ${ }^{6}$. Em relação à área de formação inicial, quatro participantes são formados em psicologia, três em história, dois em matemática, um em letras e um em fonoaudiologia. Oito tutores entrevistados trabalham como tutor de sede desde o início do curso.

Os sujeitos foram convidados a participar do estudo a partir dos seguintes critérios: ser tutor de sede que trabalha ou já trabalhou no curso durante, no mínimo, quatro semestres e que atuou em interdisciplinas diferentes da sua área de formação na graduação. Foram considerados como critérios de exclusão: tutores que trabalham ou trabalharam na interdisciplina Seminário Integrador e tutores que são formados em pedagogia. Optou-se por esses critérios de exclusão porque os tutores que trabalham na interdisciplina Seminário Integrador não se ocupam com conteúdos específicos de uma disciplina, haja vista que tal interdisciplina é responsável pela integração das demais. Já os tutores formados em pedagogia foram excluídos porque se pressupõe que eles estariam, teoricamente, amparados para acompanhar qualquer conteúdo, pois tiveram uma formação semelhante na sua graduação.

Para a coleta de dados foi utilizado um questionário com perguntas abertas e fechadas autoaplicável no qual constavam, basicamente, as seguintes perguntas: qual a área da formação do tutor na graduação?, quantos semestres trabalha ou trabalhou no curso?, se caracteriza ou não a atuação na interdisciplina na qual trabalhou como interdisciplinar?. O questionário foi enviado por e-mail aos sujeitos que preencheram os critérios para participar do estudo. Neste e-mail, os

5 Em 2009/2, o curso conta com 45 tutores de sede.

6 Optamos por utilizar o termo "tutor" nos relatos, embora grande parte dos entrevistados pertença ao sexo feminino. 
participantes foram informados dos objetivos da pesquisa e foi-lhes assegurado o anonimato das respostas, garantindo assim os princípios éticos do estudo. Foram enviados 14 questionários, sendo que 3 não retornaram.

Para a análise das respostas dos participantes, foi utilizada a análise de conteúdo (BARDIN, 1995). Através desta análise, foram destacadas as respostas dos tutores que obtiveram maior relevância, tendo em vista os objetivos deste trabalho, bem como aquelas ideias que, de alguma forma, foram mencionadas por vários entrevistados (BOGDAN e BIKLEN, 1994). A partir destes objetivos, foi abordada a seguinte temática: concepção de interdisciplinaridade. Para essa temática, foram destacadas e discutidas teoricamente as respostas de alguns participantes consideradas representativas, construindo-se, assim, categorias para a temática em questão.

\section{Análise dos Dados}

As concepções de interdisciplinaridade expressas pelos entrevistados podem ser agregadas em duas categorias: a interdisciplinaridade como relação entre diferentes áreas e/ou disciplinas e a interdisciplinaridade como conteúdo curricular e trabalho em equipe.

Na primeira categoria, interdisciplinaridade como relação entre diferentes áreas e/ou disciplinas, podemos destacar as seguintes respostas:

"É interdisciplinar sim, pois envolve conhecimentos da educação, psicologia, matemática, história..."(Tutor 10).

"Sim, pensando agora acho que isso é interdisciplinaridade. Ser formado em xxxx e trabalhar em outras áreas" (Tutor 7).

Considerando as propostas teóricas de Piaget, podemos dizer que essas concepções de interdisciplinaridade aproximam-se mais da concepção piagetiana de multidisciplinaridade. Para o autor, a multidisciplinaridade pode 
ser caracterizada como a interação entre disciplinas, mas sem que elas sejam modificadas ou enriquecidas por essa interação (PIAGET, 1972). Os participantes fazem referência, nessas respostas, ao fato de que o trabalho interdisciplinar envolve conhecimentos de outras áreas e à possibilidade de ter uma formação e atuar em campos diferentes, porém, não parecem se referir à interação entre os diversos saberes e/ou ao enriquecimento de sua própria área a partir desta relação. Envolver conhecimento de várias áreas e a possibilidade de trabalhar em áreas diversas não significa, necessariamente, que essas áreas estejam enriquecendo-se mutuamente, ou seja, estabelecendo uma assimilação recíproca, como propõe o autor.

Essa interação que possibilita um enriquecimento mútuo parece anunciar-se nas respostas seguintes, mais próximas da ideia piagetiana de interdisciplinaridade:

"A maior experiência interdisciplinar foi quando fui tutor(a) de duas disciplinas no mesmo semestre. Por isso considero interessante acompanhar duas interdisciplinas, apesar de ser mais trabalhoso. Isso favorece o aspecto da interdisciplinaridade, pois relacionamos os conceitos nas diferentes áreas, relação da qual depende a aproximação interdisciplinar" (Tutor 6).

"Acredito que sim, pois houve uma aproximação, uma relação entre duas áreas de conhecimento, um aproveitamento mútuo, digamos" (Tutor 5).

Piaget $(1971 b, 1972,1973 a)$ destaca que nas relações interdisciplinares as colaborações entre disciplinas conduzem a interações, a certa reciprocidade nas trocas que possibilitam um enriquecimento mútuo das disciplinas envolvidas. Nestas respostas, os participantes mencionam a ideia de aproximação, relacionamento entre os conceitos nas diferentes áreas e um aproveitamento mútuo. Tais ideias expressas também se aproximam da concepção de interdisciplinaridade, como integração de diferentes enfoques disciplinares, proposta por Garcia (2007). 
No que se refere à segunda categoria, interdisciplinaridade como conteúdo curricular e trabalho em equipe, destacamos as seguintes respostas:

"Diálogo entre as interdisciplinas e planejamento conjunto [...]" (Tutor 1).

Nessa resposta o tutor abrange duas dimensões na sua concepção de interdisciplinaridade: a necessidade do diálogo entre as interdisciplinas, ou seja, certo debate sobre os conteúdos que são trabalhados nas interdisciplinas e o planejamento da interdisciplinar, envolvendo diversos profissionais que representam áreas diversas. Quanto ao diálogo e ao planejamento conjunto, as interdisciplinas agregam professores e tutores, sendo que estes têm perspectivas e responsabilidades diferentes, o que exige que possa haver na equipe coordenação, sintonia nas propostas de trabalho e reconhecimento de que o saber que traz a marca de determinada disciplina é incompleto. Nesse sentido, abre-se a possibilidade de diálogo entre diversos sujeitos que trazem no seu fazer a marca de sua disciplina de formação, possibilitando o reconhecimento da complementaridade e limites de cada disciplina. É nesse sentido que Piaget (1998) menciona que no trabalho em equipe é necessário que se estabeleça a compreensão mútua e a elaboração de um vocabulário compartilhado, possibilitando esse planejamento conjunto.

Nas respostas seguintes, os participantes enfocam diretamente o conceito de interdisciplinaridade no contexto do curso e dos seus trabalhos como tutores:

“Depende. Na forma, no desenvolvimento ou no conteúdo? No desenvolvimento, talvez, tenha sido uma interdisciplina justamente por essa formação diversificada na composição das equipes de educadores. Na forma e no conteúdo talvez esteja ainda em um processo de transição, em alguns casos não existe justificativa de diferenciar disciplinas de interdisciplinas" (Tutor 8).

"A caracterização como 'interdisciplinares', no Pead, coloca-se mais como um planejamento conjunto para elaboração da grade curricular e para a aproximação dos 
pontos de chegada das disciplinas. A prática, no entanto, não propõe com consistência a ação conjunta ou conjugada das diferentes áreas" (Tutor 3).

Na primeira resposta, o participante destaca a formação diversificada na composição das equipes, ponto discutido anteriormente, como um possível promotor de uma prática interdisciplinar. $\mathrm{O}$ segundo respondente refere-se ao planejamento conjunto da proposta curricular. Pode-se dizer que ambos percebem o processo de interdisciplinaridade do curso como algo que está sendo construído, pois ainda falta consistência para sustentar essa diferenciação entre disciplinas e interdisciplinas em algumas práticas.

\section{Considerações Finais}

Neste trabalho investigamos como os tutores de sede de um curso de pedagogia na modalidade a distância, que atuam em interdisciplinas cujo conteúdo diferiu dos conteúdos comumente trabalhados em sua formação na graduação, concebem a interdisciplinaridade. A partir dessa temática, foram geradas categorias, partindo-se dos relatos dos entrevistados que participaram da pesquisa.

No que diz respeito à concepção de interdisciplinaridade, as respostas dos participantes indicaram que eles tendem a conceber as relações entre conteúdos/disciplinas diversas como interdisciplinar, porém tais concepções aproximam-se mais da noção piagetiana de multidisciplinaridade (PIAGET, 1972). Por outro lado, alguns sujeitos parecem aproximar-se da noção de interdisciplinaridade quando mencionam o relacionamento entre conceitos e o aproveitamento mútuo das disciplinas. Os participantes também fizeram uma ligação entre o conceito de interdisciplinaridade com o conteúdo curricular do curso e com o trabalho em equipe. Nessa categoria, foi debatida a necessidade de formação de equipes para tornar possível a implementação de trabalhos interdisciplinares, conforme propõe Garcia (2007). Finalmente, foi mencionada 
a noção de interdisciplinaridade vinculada diretamente ao contexto do curso e do trabalho dos tutores. Nessa categoria, em especial, os entrevistados ressaltaram a formação diversificada na composição das equipes como possível indicador de uma prática interdisciplinar, referindo que os processos interdisciplinares do curso ainda estão em construção.

A partir dos dados obtidos neste trabalho, abarcamos alguns aspectos acerca da prática interdisciplinar de tutores de sede, vinculados a um curso na modalidade a distância. Com este trabalho estamos longe de esgotar o debate sobre a função dos tutores nos cursos de educação a distância, tampouco sobre o conceito de interdisciplinaridade. Os dados apresentados representam uma aproximação com essas temáticas, demonstrando que esses assuntos podem ser concebidos como atuais e relevantes, principalmente para o campo educacional. 


\section{Referências}

BARDIN, L. Análise de Conteúdo. Lisboa: Edições 70, 1995.

BOGDAN, Robert C.; BIKLEN, Sari Knopp. Investigação qualitative em educação: uma introdução à teoria e aos métodos. Portugal: Porto Editora, 1994.

BRASIL. Referenciais de qualidade para educação superior a distância. Brasília, 2007. Disponível em: http://portal.mec.gov.br/seed/arquivos/pdf/legislacao/refead1.pdf. Acesso em: março 2008.

CHARCZUK, S. B; NEVADO, R. A. O conceito de interdisciplinaridade em Jean Piaget: questões teóricas e contribuições para o âmbito educativo. Anais do I Colóquio Internacional de Epistemologia e Psicologia Genéticas: atualidade da obra de Jean Piaget. Marília: UNESP/FFC, 2009, p.42-52.

GARCIA, R. Sistemas Complejos: conceptos, método y fundamentación epistemológica de la investigación interdisciplinaria. Barcelona: Gedisa Editorial, 2007.

MACHADO, L. D; MACHADO, E. C. O papel da tutoria em ambientes de EAD. Disponível em: http:/ /www.abed.org.br/congresso2004/por/htm/022TC-A2.htm. Acesso em: agosto 2009.

NEPOMUCENO, K. S. M; SALLES, M. F. R.; PAN, M. C. O. As concepções sobre a função do tutor influenciam o processo ensino-aprendizagem em EAD? Disponível em: http:/ / www.abed.org.br/congresso2004/por/htm/004TC-A2.htm. Acesso em: agosto 2009.

NEVADO, R. A.; CARVALHO, M. S.; BORDAS, M. C. Licenciatura em Pedagogia a Distância: anos iniciais do ensino fundamental. Guia do tutor. PEAD/UFRGS: Gráfica da UFRGS, 2006.

PIAGET, J. Observações psicológicas sobre o trabalho em grupo. In: PARRAT, S.; TRYPHON, A. Sobre a pedagogia: textos inéditos. São Paulo: Casa do Psicólogo, 1998.

PIAGET, J. Problemas gerais da investigação interdisciplinar e mecanismos comuns. Lisboa: Livraria Bertrand, 1973a.

PIAGET, J. Estudos Sociológicos. Rio de Janeiro: Editora Forense, 1973b.

PIAGET, J. L'epistemologie des relations interdisciplinaires. In: APOSTEL, L.; BERGER, G.; BRIGGS, A.; MICHAUD, G. (org.). L'interdisciplinarité: 
problemes d'enseignement et de recherche dans les universites. Paris - France, Organization de Coperation et developpement Économiques, 1972.

PIAGET, J. Où va l'éducation? Folio Essais, 1971a.

PIAGET, J. Méthodologie des relations interdisciplinaires. Archives de Philosophie, 34, 1971b, p. 539-549.

PIAGET, J. La psychologie, les relations interdisciplinaires et le systeme des sciences. Bulletin de psychologie, 20, nº. 254, 1966, p. 242-254.

THIESEN, J. S. A interdisciplinaridade como um movimento articulador no processo ensino-aprendizagem. Revista Brasileira de Educação, v. 13 n. 39, set./dez. 2008, p. 545-554.

YIN, R. K. Estudo de Caso. Porto Alegre: Bookman, 2005.

ZIEDE, M. K. L. A construção da função dos tutores no âmbito do curso de graduação em pedagogia: licenciatura na modalidade a distância da Faculdade de Educação. Dissertação de Mestrado. Universidade Federal do Rio Grande do Sul, 2008. 